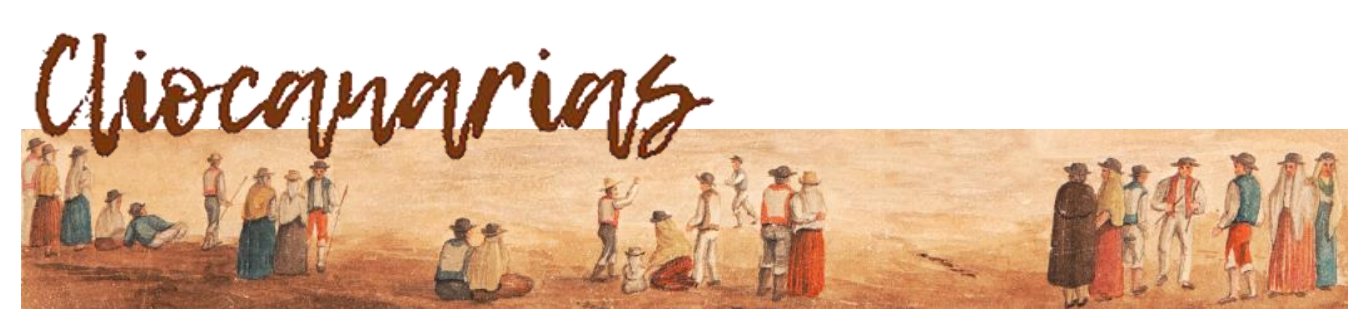

ISSN 2695-4494

https://doi.org/10.53335/cliocanarias.2021.3.04

\title{
DESCUBRIENDO LO DESCONOCIDO. LA NAVEGACIÓN EUROPEA EN EL GRAN CARIBE DURANTE LA ÉPOCA DE LOS VELEROS
}

\author{
DISCOVERING THE UNKNOW. EUROPEAN NAVIGATION \\ IN THE GREAT CARIBBEAN DURING THE SAILING AGE
}

Rafal REICHERT*

RESUMEN: En este artículo se presenta la cuestión de la navegación europea por el Gran Caribe a partir de los primeros viajes de Cristóbal Colón hasta el siglo XVII cuando otras potencias del Viejo Mundo, como Francia, Inglaterra y Holanda comenzaron a explorar y establecerse en el Mare Clausum hispano. Con base en la historiografia seleccionada se exponen elementos descriptivos del paisaje marítimo, rutas de navegación y primeros siniestros que ocurrieron en el Gran Caribe, el espacio que durante la época de vela fue considerado el núcleo que conectaba intereses europeos con el mundo americano.

PALABRAS CLAVE: Gran Caribe, Nuevo Mundo, navegación europea, exploración, naufragios.

ABSTRACT: This article presents the question of the European navigation through the Greater Caribbean from the first voyages of Christopher Columbus till the seventeenth century, when other Old World maritime powers, such as France, England and the Netherlands, began to explore and settle in the Hispanic Mare Clausum. The text, based on the selected historiography, descripts some examples of the maritime landscape, navigation routes and first accidents that occurred in the Greater Caribbean, the area that during the Sailing Age was considered the nucleus who connected European interests with the American world.

KEYWORDS: Greater Caribbean, New World, European navi-gation, exploration, shipwrecks.

\footnotetext{
* Profesor-investigador (Instituto de Estudios Ibéricos e Iberoamericanos, Universidad de Varsovia, Polonia).C. e.: rafreich@yahoo.com
} 


\section{Introducción}

Desde la segunda mitad del siglo XV, la curiosidad, la inquietud y el espíritu aventurero llevaron a los europeos a emprender grandes empresas de búsqueda de nuevas rutas maritimas que comunicaran Europa con Asia. En aquel entonces, el entusiasmo por dominar lo desconocido llevó, principalmente a los portugueses y españoles, a encontrar un camino alternativo hacia Cipango, China y la India. Sorprendentemente, a pesar de encontrar el paso al Oriente por el cabo de Buena Esperanza - el extremo sur del continente africano que separa el océano Atlántico del Índico-, que recorrió Bartolomé Díaz en $1488^{1}$, los desafios maritimos llevaron a los pueblos ibéricos al descubrimiento de un nuevo mundo.

El hombre que lo efectuó fue un genovés, Cristóbal Colón, quien con el apoyo de los Reyes Católicos - Fernando e Isabel- en 1492 cumplió con sus sueños de ir más allá del horizonte y navegar hacia occidente para encontrar una nueva ruta al lejano Oriente. Curiosamente, el navegante nunca llegó a su destino deseado; sin embargo, el "descubrimiento" o el "encuentro" que materializó, cambió para siempre la historia del mundo moderno y contemporáneo. Colón, conocido por su gran espíritu aventurero y limitada capacidad administrativa, pronto cayó en desgracia real. Tras realizar su cuarto y último viaje a las Indias (1502-1504) regresó a España, donde se encontró con cierta desconsideración y descrédito, circunstancia que acarreó una última etapa de su vida poco halagüena. Como a la historia de la humanidad no le gustan espacios vacios, irónicamente las tierras que descubrió el genovés se bautizaron con un nombre, América, en honor del cosmógrafo, navegante y primer piloto mayor de la Casa de Contratación ${ }^{2}$ Américo Vespucio, quien realizó por lo menos dos viajes de reconocimiento y exploración del Nuevo Mundo. Las expediciones le permitieron describir sus experiencias en dos obras: Mundus Novus y Carta a Soderini ${ }^{3}$.

Sin embargo, los esfuerzos por el descubrimiento de lo desconocido en los inmensos espacios marítimos del Atlántico que iniciaron los viajes precursores de Bartolomé Díaz, Cristóbal Colón, Vasco da Gama y Fernando Magallanes, entre otros, no hubieran sido posibles sin el gran desarrollo científico y tecnológico del Renacimiento, manifestado a través de nuevos instrumentos (ballestilla y astrolabios) que se emplearon en los campos de la cartografia náutica y astronomía, tanto en España como en Portugal ${ }^{4}$. A esto se añade que a partir del siglo XV comenzó una época dorada de la construcción naval de ambos Estados ibéricos. Así, el empleo de nuevas técnicas para fabricar cascos grandes, de mayor calado y más sólidos, permitió el mejor uso del velamen y de las jarcias para cumplir con las necesidades de realizar los viajes transatlánticos. Es perceptible una evolución en los buques, que cambiaron su estilo desde la

${ }^{1}$ FAVIER, Jean: Los grandes descubrimientos. De Alejandro a Magallanes, México, 1995, FCE, p. 342.

2 La institución creada en 1503 por los Reyes Católicos para monopolizar, controlar y regular el tráfico con las Indias.

${ }^{3}$ FERNÁNDEZ ARMESTO, Felipe: Amerigo. The man who gave his name to America, London, Weidenfeld \& Nicolson, 2006, pp. 172-173.

${ }^{4}$ LÓPEZ PIÑERO, José María: El arte de navegar en la España del Renacimiento, Barcelona, Editorial Labor, 1979, p. 34. 
coca medieval a la nao, las carracas, y finalmente al galeón, el logro más importante de la industria naviera ibérica ${ }^{5}$.

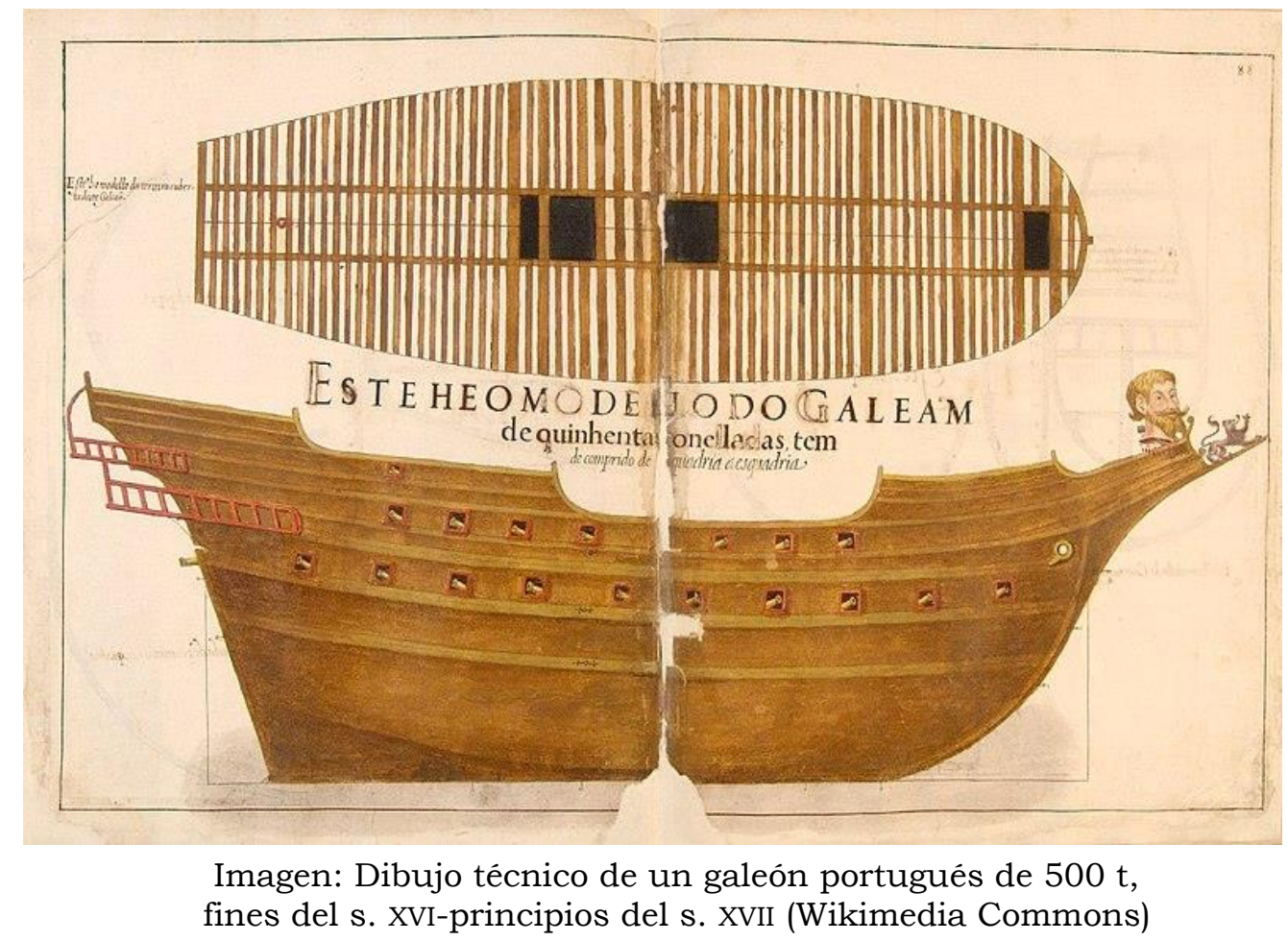

\section{E1 Caribe, corazón del mundo atlántico}

Es esencial subrayar que desde los primeros dos viajes de Colón se estableció una nueva ruta náutica, que a lo largo de la época de vela fungió la función de "un corredor marítimo" a través del cual se comunicaron los continentes que circundan el Atlántico. Es decir, a través de la navegación por este océano fue posible conectar Europa, África y ambas Américas dentro de un sistema global a nivel geopolítico, económico, naval, militar y sociocultural, que hoy la historiografia presenta como un mundo atlántico.

Se puede decir que a lo largo de la época colonial (siglos XVI-XIX) el Caribe fue considerado por España, pero también por otras potencias marítimas europeas (Inglaterra, Francia y Holanda), como el corazón del Nuevo Mundo, en el que se concentraban y reunían los recursos, tanto humanos (colonizadores y esclavos africanos) como materiales (mercancías europeas) y naturales (metales preciosos y frutos de la tierra) provenientes de todos los continentes, para que después se distribuyeran según las necesidades entre Europa y las Indias. Cabe decir que desde 1564, cuando se estableció la ruta del galeón de Filipinas o nao de China por el Mar del Sur (el Pacífico), la cuenca caribeña adquirió un nuevo rol: el de intermediación en el comercio de España con el lejano Oriente que se realizaba a través de Acapulco, la ciudad de México y

5 ODRIOZOLA OYARBIDE, Lourdes: Construcción naval en el País Vasco, siglos XVI-XIX. Evolución y Análisis, San Sebastián, 1996, p. 47. 
Veracruz, este último puerto ubicado en el golfo de México y punto estratégico en las comunicaciones marítimas con la metrópolí.

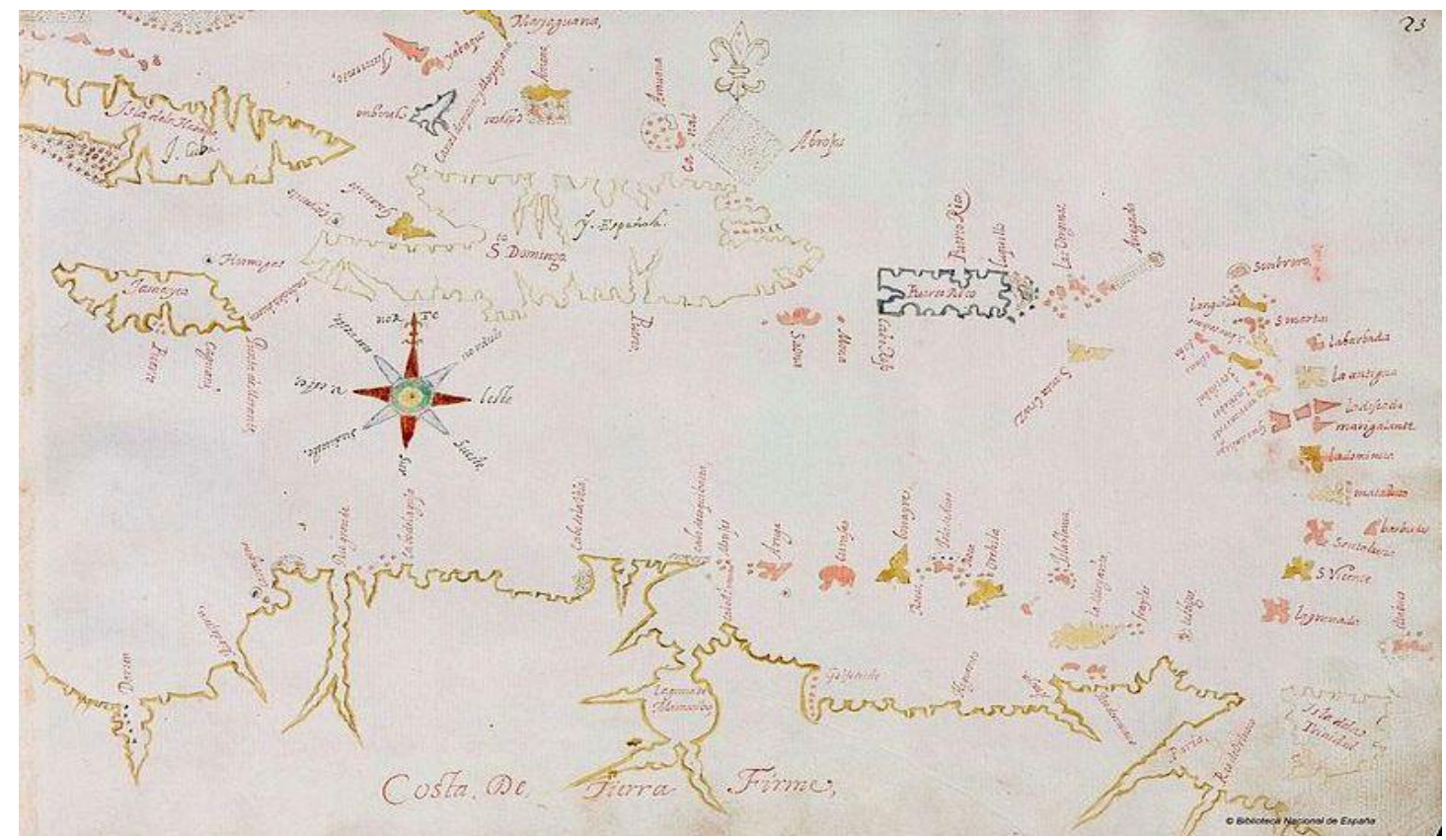

Imagen: Costa de Tierra Firme y Antillas (mapa del capitán Nicolás Cardona, 1632) (Wikimedia Commons)

Finalmente, es muy importante que percibamos el Caribe como una región compleja del mundo atlántico, sin limitarla solamente a las Antillas Mayores y Menores, contemplándola tanto desde el punto de vista histórico y geopolitico como desde el sociocultural y económico, lo que subrayan en sus aportaciones los principales investigadores de la región como Carl Ortwin Sauer, Eric Williams, Juan Bosch, John H. Parry y Philip M. Sharlock, Johanna von Grafenstein, entre otros, quienes denominan a esta subregión atlántica como el Gran Caribe o Circuncaribe o Golfo-Caribe. Con ello consideramos que la región la conforman dos espacios marítimos: el Golfo de México y el Mar Caribe, que con sus litorales se expanden desde el sur de los actuales Estados Unidos de América, pasan por México y países centroamericanos, para llegar a la parte septentrional de América del Sur, las Antillas Menores y Mayores, además de las Guyanas.

\section{Primeras exploraciones españolas en el Caribe}

Con la llegada de Cristóbal Colón a las Antillas, la Corona española adquirió el monopolio sobre los territorios recién descubiertos, que formalizó mediante el tratado de Tordesillas (1494). Se puede decir que a partir del primer viaje del Almirante del Mar Océano comenzó una imparable exploración de los litorales del Caribe que terminó con las conquistas de las islas de las Antillas Mayores y Tierra Firme. En este proceso de descubrimientos náuticos, además de los españoles, participaron de manera muy activa los portugueses e italianos ${ }^{7}$.

${ }^{6}$ HARING, Clarence H.: Comercio y navegación entre España y las Indias, México, FCE, 1984, p. 182.

${ }_{7}^{7}$ BOORSTIN, Daniel: Los descubridores, Barcelona, Editorial Crítica, 1983, p. 178. 
Es interesante mencionar que solamente el primer viaje de Colón se realizó por una ruta diferente, en la cual el genovés no aprovechó la corriente ecuatorial norte del Atlántico; sin embargo, a partir de su segundo viaje el Almirante estableció la travesía desde España (Sevilla y Cádiz) por la vía de las islas Canarias, costa occidental de África hasta las islas de Cabo Verde, donde la ruta giraba hacia el oeste y después - aprovechando la corriente del Caribe - llegaba a la pequeña isla llamada La Deseada, que forma parte del arco del Caribe, es decir, las Antillas Menores.

Retornando a las exploraciones españolas en la cuenca caribeña, estas se centraron en la incursión por Tierra Firme, donde todavía - hasta el viaje de Juan Díaz de Solís y Vicente Yáñez Pinzón (1508-1509) - se buscaba el paso hacia la especeria. A partir de este reconocimiento llevado a cabo por el veterano marino de viajes colombinos y patrocinado por la Casa de Contratación de Sevilla, comenzaron las empresas enfocadas hacia la obtención de "reparto" 8 y colonización. Con ello, el Caribe se convierte en un espacio de navegación de cabotaje, cuyo puerto de partida fue Santo Domingo de Guzmán en La Española, el primer núcleo del poder naval y administrativo español en las Indias, lugar que todavía fue escogido para este fin por Cristóbal Colón durante su primer viaje. Tras fracasar en el establecimiento de las primeras poblaciones españolas (La Navidad e Isabel) en la vertiente septentrional de la isla, en agosto de 1496 se trasladaron todos los colonos, bajo el mando de Bartolomé Colón, a la costa meridional, donde se asentaron en la margen oriental de la desembocadura del río Ozama, para acabar desplazado seis años más tarde por Nicolás de Ovando a la margen occidental del mismo río y su actual localidad ${ }^{9}$.

Desde entonces la isla se convirtió en el principal núcleo del poder administrativo español en las Indias mediante la Audiencia y la Cancillería Real de Santo Domingo, creada en 1511, y bajo su jurisdicción tuvo todas las tierras americanas hasta el momento descubiertas. Además, debido a su ubicación en la desembocadura del río Ozama y las buenas condiciones portuarias, Santo Domingo de Guzmán se convirtió en un importante puerto de la navegación colonial española a donde, hasta los años treinta del siglo XVI, arribaban todas las embarcaciones provenientes de la metrópoli cargadas de mercancías españolas y europeas. Desde este punto se llevaban a otros lugares de creciente envergadura como Cuba, Jamaica, Puerto Rico, Tierra Firme y Panamá ${ }^{10}$. Finalmente, es importante destacar que de este puerto salian las expediciones de exploración de la cuenca caribeña, con sus islas y costas continentales. Las incursiones permitieron crear contacto con la población indigena, y además dieron paso a la fundación de nuevos asentamientos hispanos en los litorales del Gran Caribe.

\footnotetext{
8 Por un lado se refiere al botín de metales preciosos y otros obsequios de valor, y por otro a los indios apresados con el fin de llevarlos a La Española como esclavos (MACÍAS RICHARD, Carlos: El Caribe mexicano. Origen y conformación, siglos XVI y XVII, Chetumal-México, Universidad de Quintana Roo-Porrúa, 2006, pp. 72-73).

9 ORTWIN SAUER, Carl: Descubrimiento y dominación española del Caribe, México, FCE, 1984, pp. 221-223.

10 BOSCH, Juan: De Cristóbal Colón a Fidel Castro. El Caribe, frontera imperial, México, Porrúa, 2009, pp. 135-139.
} 
Respecto a la navegación en esta cuenca maritima, se puede decir que durante la época de los veleros era el corazón de las actividades náuticas debido a su ubicación geográfica en el Atlántico, ya que las corrientes y vientos empujaban las embarcaciones desde la costa africana más o menos a la altura de Cabo Verde, y permitian cruzar el océano para alcanzar el Caribe en torno a las Antillas Menores. Los navegantes, una vez en este espacio maritimo, todavía aprovechaban la corriente del Golfo, que les llevaba dentro del mar antillano y el golfo mexicano para que, a la latitud de Florida, las embarcaciones pudieran ser impulsadas por el canal de Bahamas al Atlántico del Norte y a Europa ${ }^{11}$.

Además de las fuertes corrientes maritimas, el Gran Caribe se caracteriza por su multitud de islas e isletas, que en el norte y oriente forman el limite natural de este espacio marino, conjunto que — con los bajos, cayos y arrecifes - representaba un gran peligro para la navegación a vela. Fue un factor que junto con los huracanes, tempestades y nortes causó numerosos siniestros marítimos, de manera que el mar caribeño "acobijó" centenares de naufragios en su fondo. El mejor temprano ejemplo lo proporciona la nao Santa María, que durante el primer viaje de Cristóbal Colón al Nuevo Mundo encalló el 25 de diciembre de 1492 por la parte de proa en un arrecife de la actual bahía Caracol en la isla de La Española ${ }^{12}$. Así describió el propio Almirante este primer siniestro marítimo en el Nuevo Mundo:

Martes, 25 de diciembre, dia de Navidad:

Navegando con poco viento el día de ayer desde la mar de Santo Tomé hasta la Punta Santa, [...] acordó echarse a dormir, porque habia dos dias y una noche que no habia dormido. Como fuese calma, el marinero que gobernaba la nao acordó irse a dormir también, y dejó el gobierno a un mozo grumete, lo que mucho siempre habia el Almirante prohibido en todo el viaje [...]. El Almirante estaba seguro de bancos y de peñas, porque el domingo, cuando envió las barcas a aquel rey, habian pasado al este de la dicha Punta Santa bien tres leguas y media, y habian visto los marineros toda la costa y los bajos que hay desde la dicha Punta Santa al este bien tres leguas, y vieron por dónde se podia pasar, lo que todo este viaje no hizo. Quiso Nuestro Señor que a las doce horas de la noche, como habian visto acostar y reposar el Almirante y veian que era calma muerta y la mar como en una escudilla, todos se acostaron a dormir, y quedó el gobernalle en la mano de aquel muchacho, y las aguas que corrian llevaron la nao sobre uno de aquellos bancos. Los cuales, puesto que fuese de noche, sonaban que de una grande legua se oyeran y vieran, y fue sobre él tan mansamente que casi no se sentía. El mozo, que sintió el gobernalle y oyó el sonido de la mar,

\footnotetext{
11 El descubrimiento de la corriente del Golfo data de 1513, y lo notó Juan Ponce de León durante su expedición. El explorador, navegando hacia el sur a lo largo de las costas orientales de Florida, con viento en popa (aunque débil) se dio cuenta de que su embarcación retrocedía en lugar de avanzar. A partir de este momento, la corriente fue continuamente utilizada por los navegantes europeos durante su viaje de vuelta del Gran Caribe a Europa.

12 ELIOT MORISON, Samuel: El Almirante de la Mar Océano. Vida de Cristóbal Colón, México, FCE, 1991, p. 414
} 
dio voces, a las cuales salió el Almirante, y fue tan presto que aún ninguno habia sentido que estuviesen encallados. [...] Cuando el Almirante vio que [...] las aguas menguaban y estaba ya la nao la mar de través, no viendo otro medio, mandó cortar el mástil y alijar de la nao todo cuanto pudieron para ver si podian sacarla; y como todavía las aguas menguasen no se pudo remediar, y tomó lado hacia la mar traviesa, puesto que la mar era poco o nada, y entonces se abrieron los conventos $^{13}$ y no la nao ${ }^{14}$.

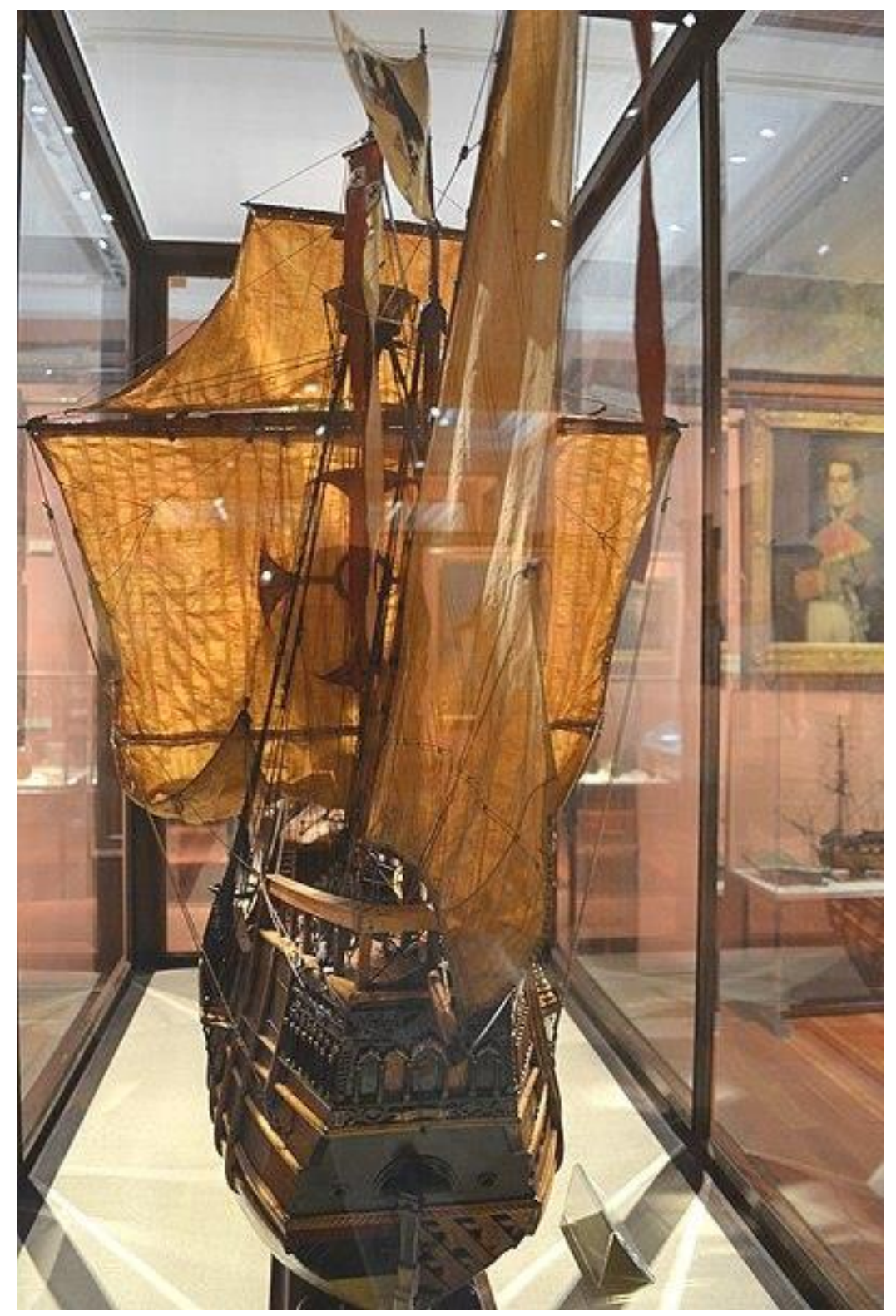

Imagen: Modelo de la nao Santa María (Museo Naval de Madrid, Wikimedia Commons)

Retornando al tema de la navegación circuncaribeña, ya se ha mencionado el viaje de reconocimiento de Díaz de Solís y Yáñez Pinzón, que comprobó que el Caribe no tiene una conexión directa con el océano Pacífico. Al mismo

13 Abrirse las costuras de los tablones.

14 COLÓN, Cristóbal: Diario de a bordo, Madrid, Grupo EDAF, 2006, pp. 194-195. 
tiempo surgen otras navegaciones de reconocimiento y conquista, como la proveniente de Santo Domingo hacia Jamaica, llevada a cabo por Juan de Esquivel en 1509; hacia Cuba, emprendida por Diego Velázquez Cuéllar en 1511; y hacia Veragua y Nueva Andalucía (actuales Panamá y Colombia), capitaneadas por Alonso de Ojeda y Diego Nicuesa en 1509. Cabe mencionar que Ojeda, entre los años 1499 y 1502, también realizó dos viajes de exploración por las costas de la actual Venezuela. Además, entre los años 1504-1506, el piloto más experimentado en la navegación caribeña, Juan de la Cosa, exploró el golfo de Urabá, un espacio geográfico mejor conocido como Darién ${ }^{15}$. Añadamos que los reconocimientos de Jamaica y Cuba eran más favorables para los españoles, quienes rápidamente se instalaron en ambas islas. Lo opuesto encontraron las expediciones en Veragua y Nueva Andalucía, donde tuvieron que enfrentarse contra indigenas feroces y un clima muy insalubre. A pesar de esas condiciones, los hispanos lograron fundar en 1510 la primera villa en Tierra Firme, Santa María la Antigua (Darién), lugar que permitió seguir la conquista hacia el Mar del Sur, descubierto por Vasco Núñez de Balboa tres años más tarde.

A partir de esos acontecimientos se fortalece la idea de conquistar nuevos territorios para seguir ampliando el poder español en el Nuevo Mundo, la búsqueda de las riquezas y la evangelización de los indios. Se intensificó entonces la navegación con la metrópoli, sobre todo circuncaribeña, un hecho que también se reflejó en las relaciones sobre accidentes marítimos en esa cuenca. Un ejemplo lo hallamos en "El libro 50 de la Historia general y natural de las Indias, islas y tierra firme del mar océano", de Gonzalo Fernández de Oviedo y Valdés, donde el autor describió con detalle algunos siniestros y desastres ocurridos en el Golfo-Caribe en la primera mitad del siglo XVI. Entedemos que es significativo presentar una de sus narrativas sobre esos momentos trágicos que vivieron los primeros españoles en el Caribe:

En el año 1513 partió una nao del puerto de esta ciudad de Santo Domingo de la isla Española para ir al Darién, que era una ciudad a una legua de la costa del golfo de Urabá [...], la cual poco tiempo antes habian ganado los cristianos, y estaba alli por capitán Vasco Núñez de Balboa. Esta nao iba con muchas mercaderias y pasajeros y marineros, que por todos eran cincuenta o sesenta personas; $y$ por sus pecados y por no ser el piloto cual habia de ser, erraron la derrota y fueron a reconocer la Tierra Firme cien leguas o más abajo del Darién, y no conoció el piloto ni hombre de ellos en qué parte estaban, y cargó tanto el tiempo, que dio con ellos y con la nao al través en la costa, y se perdió la nao y todo lo que llevaban; pero se salvó la gente aunque con trabajo ${ }^{16}$.

Esta descripción nos acerca a un problema grave que tuvieron que enfrentar los hombres del mar en aquellos tiempos; nos referimos a los errores de la navegación que en múltiples ocasiones fueron la consecuencia de un escaso

15 ORTWIN SAUER, Carl: Descubrimiento y dominación..., op. cit., pp. 245-259.

16 FERNÁNDEZ DE OVIEDO Y VALDÉS, Gonzalo: Historia general y natural de las Indias, islas y tierra firme del mar océano, tercera parte, tomo IV, Madrid, Imprenta de la Real Academia de la Historia, 1855, pp. 467-468. 
conocimiento cartográfico e insuficiente preparación náutica de los pilotos y maestros que entonces surcaban las aguas caribeñas. Para enfrentar este inconveniente, la Casa de Contratación, a partir de 1508, creó el puesto de piloto mayor, cargo que ocupaban los catedráticos de cosmografia, matemática y ciencias náuticas con navegantes experimentados durante las navegaciones transatlánticas. A este centro de estudios tuvieron que asistir todos los pilotos de la Carrera de Indias para instruirse en el arte de la navegación. Al finalizar su educación se les practicaba un examen que acreditaba sus conocimientos y capacidades para realizar las travesias transoceánicas. Asimismo, los examinados obtenían el grado de piloto, necesario para convertirse en el responsable técnico de un buque que navegaba a las Indias ${ }^{17}$.

Regresando a la navegación por el Gran Caribe, y como lo subrayan Carl Ortwin Sauer y Carlos Macias Richard, es importante el hecho de que a partir de las expediciones a Veragua y Nueva Andalucia, además de las conquistas de Jamaica, Cuba y Puerto Rico, se incrementaron las expediciones hacia el litoral sur del Caribe, pero sobre todo hacia Panamá, Centroamérica y actual México.

\section{Navegación española por el golfo de Honduras y la parte suroriental de la peninsula de Yucatán}

Después del cuarto viaje de Colón (1502-1504) y el reconocimiento que acometieron Juan Diaz de Solís y Vicente Yáñez Pinzón (1508-1509), prácticamente fueron descubiertos los litorales centroamericanos, lo que dio nuevo impulso para comenzar la conquista hacia tierra adentro. Todavía antes del proceso de colonización se llevaron a cabo dos importantes reconocimientos náuticos que influyeron en el destino de los pueblos indígenas de la región. Se trata de las expediciones de Francisco Hernández de Córdoba y Juan de Grijalva.

Ambas empresas fueron preparadas y amparadas por el gobernador de Cuba, Diego Velázquez de Cuéllar, quien según las palabras de Bernal Díaz del Castillo envió [a Hernández de Córdoba] a las islas de los Guanajes a cautivar indios por fuerza, para servirse de ellos como esclavos ${ }^{18}$. La confirmación del propósito de dicho viaje también lo podemos encontrar en Documentos cortesianos, escritos por el futuro conquistador de México, Hernán Cortés ${ }^{19}$. De ese modo, en febrero de 1517 Francisco Hernández de Córdoba salió de Santiago de Cuba comandando una escuadra de dos buques con 110 soldados y marineros hacia occidente. Sin embargo, debido a un temporal la armada se encontró con una nueva costa hasta el momento desconocida, es decir, con la parte nororiental de Yucatán. De Cabo Catoche los barcos transitaron la ruta de cabotaje hacia el noroeste de la península, llegando hasta Potonchán (ac-

\footnotetext{
17 GARCÍA GARRALÓN, Marta: «La formación de los pilotos de la Carrera de Indias en el siglo XVIII", en Anuario de Estudios Atlánticos, núm. 55, Las Palmas de Gran Canaria, 2009, pp. 161-162.

18 DÍAZ DEL CASTILLO, Bernal: Historia verdadera de la conquista de la Nueva España, Madrid, Espasa-Calpe, 1975, p. 4.

19 MARTÍNEZ, José Luis: Hernán Cortés, Documentos Cortesianos, México, FCE-UNAM, 1990, p. 223.
} 
tual Champotón), el lugar donde la compañía de Hernández de Córdoba combatió contra los indígenas. Después de una feroz escaramuza, el comandante español decidió regresar a Cuba ${ }^{20}$.

Las noticias que trajo consigo sobre nuevas tierras y un pueblo avanzado socialmente (desde entonces conocido como los mayas), animaron a Diego Velázquez de Cuéllar a enviar una nueva expedición, ahora bajo el mando de Juan de Grijalva. Según Carlos Macias Richard, la nueva empresa se produjo en un tiempo relativamente corto debido a la gran esperanza de encontrar oro en el territorio apenas descubierto por Hernández de Córdoba. Esta noticia sobre la abundancia de dicho metal precioso la divulgó entre los españoles un cautivo indio llamado Melchorejo. Además, el interés se incrementó por los intereses propios del gobernador y su gente, quienes deseaban enriquecerse y sacar mayor provecho de las nuevas tierras para colmar sus ambiciones. Así, una vez más, el objetivo principal de la expedición se enfocó hacia el acopio de metales preciosos, y secundariamente en la conquista y el establecimiento de poblados españoles en Yucatán ${ }^{21}$.

De esa manera, en mayo de 1518 salieron tres carabelas ${ }^{22}$ de la punta San Antón en Cuba rumbo a Yucatán para emprender una nueva aventura en dicha área. Después de tres días de navegación los españoles vieron la tierra que identificaron como una isla con un golfo navegable y la bautizaron Santa Cruz (actual Cozumel). En aquel lugar los españoles, mediante Melchorejo y Julianillo, los traductores apresados por Hernández de Córdoba, trabaron contacto amistoso con la población indígena, que también les informó de que en la costa había hombres parecidos a ellos ${ }^{23}$. La expedición de Grijalva, guiada por el piloto mayor Antón de Alaminos ${ }^{24}$, un veterano y gran conocedor de las aguas circuncaribeñas, se encaminó primero hacia el suroeste, llegando hasta la bahía de Ascensión. Sin embargo, los españoles no decidieron mantener el rumbo; solo regresaron a la isla Mujeres y de allá se dirigieron al Golfo de México, costeando la península de Yucatán, llegando a la laguna de Términos, Coatzacoalcos, San Juan de Ulúa y Pánuco. En esta última localidad los guerreros indigenas, en 16 canoas, atacaron a una de las embarcaciones de Juan de Grijalva, hiriendo a algunos de los expedicionarios. Después de este hecho, Alaminos y varios de los soldados optaron por regresar a Cuba, lo que

20 CHAMBERLAIN, Robert S.: Conquista y colonización de Yucatán (1517-1550), México, Porrúa, 1982, pp. 13-15.

${ }^{21}$ MACÍAS RICHARD, Carlos: El Caribe mexicano. Origen y conformación..., op. cit., pp. 83-84.

${ }^{22}$ Cabe señalar que dos de las tres carabelas participaron un año antes en la aventura de Hernández de Córdoba, y la mayoría de la gente de aquella expedición se alistó nuevamente en la empresa bajo el mando de Juan de Grijalva.

23 Se trata de Gonzalo Guerrero y Gerónimo de Aguilar, los náufragos del buque comandado por Juan de Valdivia que en 1511 se dirigía a Santo Domingo con los obsequios para el gobernador y pedir gente y viveres para los pobladores españoles en Darién. Sin embargo, a causa de un temporal la nao naufragó en los bajos de Víboras, cerca de la isla de Jamaica, y los sobrevivientes del siniestro fueron llevados en un bote a la costa yucateca, donde los capturaron los mayas.

${ }^{24}$ Antón de Alaminos era uno de los pilotos más experimentados en la navegación por el Gran Caribe, ya que su conocimiento náutico en esta cuenca marítima comenzó a formarse con el cuarto viaje de Colón en 1502. Después realizó varios viajes menores, pero también navegó con Ponce de León en el viaje del descubrimiento de Florida, y finalmente guio por las aguas yucatecas la expedición de Hernández de Córdoba. 
se fraguó en pocos días, intentando el comandante español seguir la misma ruta de retorno. Todavía la expedición visitó el río Lagartos y un poblado llamado Coní, desde donde navegaron hacia la isla cubana el 29 de septiembre de 1518 para anclar en Santiago de Cuba25.

En este punto, para acercarnos al ambiente de navegación en aquellos tiempos por aquel mar yucateco recién descubierto, parece importante presentar la descripción de Gonzalo Fernández de Oviedo y Valdés sobre los sucesos que vivió el licenciado Alonso Zuazo. Este fue enviado en enero de 1524 desde Santiago de Cuba a Nueva España para resolver el desacuerdo entre Francisco de Garay —nombrado gobernante de la provincia del Pánuco-, y Hernán Cortés, quien estuvo ocupando este territorio desde la conquista de México. Con objeto de evitar un agravamiento del conflicto, el gobernador de Cuba recomendó el envío del licenciado, que entonces era su teniente, para que negociara y llegara a un acuerdo con el fundador de la Nueva España. El oficial real subió a una carabela de 45 toneladas y desde Santiago se dirigió a la punta de San Antón en Cuba, el lugar más cercano de la isla a las costas yucatecas, con el fin de navegar hacia cabo Catoche y alcanzar San Juan de Ulúa. Los sucesos deparados en este viaje con su carabela los describe así el gran cronista indiano:

[...] Del Cabo de San Antón siguió su navegación para Nueva España; y estando engolfado y habiéndole sucedido contrarios tiempos, siguiese que después de haber navegado mucho tiempo, un día a la media noche, que se contaron 20 del mes de enero de 1524, les dio tan recio temporal y tormenta, que muchas veces se vieron cubiertos de las ondas de la mar, asi por ser grande la tormenta como por ser tan pequeña la carabela [...]. Y asi, en el instante parecía que el navio salia del profundo de la mar hasta encima de ella; y veian entre la noche oscura una luz que les guiaba [...]. Sin saber a dónde estaban ni poder gobernar el navio, ni se poder aprovechar del aguja ni cuadrante ni de otra cosa en que pudiese quedarles confianza de salud alguna, más de sólo remitirse a Dios y dejarle hacer, porque en él sólo confiaban y no en el arte y diligencia del piloto y marineros [...]. Y al cuarto del alba otro dia dieron en unos bajos y arrecifes de peñas bravas y muy áspe$\operatorname{ras}^{26}$.

Los náufragos se encontraron en un archipiélago de tres isletas, bajos de arena y arrecifes, donde pasaron casi cuatro meses cambiando su posición de una isla a otra, comiendo carne cruda de lobos marinos, tortugas y aves, así como los huevos de estas dos últimas especies, y de vez en cuando pescando tiburones. Según la relación que narró Alonso Zuazo a Fernández de Oviedo, los sobrevivientes de este accidente se encontraron en el sistema de arrecifes de los Alacranes, en la entrada al Golfo de México. Sin embargo, esto no es seguro, lo que señala el propio cronista indiano en el apartado XXVI de la descripción del accidente de la carabela, diciendo que: [...] No me apartando

${ }^{25}$ MACÍAS RICHARD, Carlos: El Caribe mexicano. Origen y conformación..., op. cit., pp. 102106.

${ }^{26}$ FERNÁNDEZ DE OVIEDO Y VALDÉS, Gonzalo: Historia general y natural de las Indias..., op. cit., p. 484. 
de mi opinión, que es que estos [Zuazo y otros náufragos] no se perdieron ni estuvieron en ellas [islas de los Alacranes] sino en las del Triángulo, como de suceso lo he apuntado; pero pues el licenciado siempre me dijo que eran las de los Alacranes, por eso hablemos de ellas. Con esta opinión coincide la arqueóloga marítima Vera Moya Sordo, quien asocia el accidente marítimo al que sobrevivió Alonso Zuazo con un pecio llamado Pilar, que se encuentra en los Triángulos en la Sonda de Campeche, y que mediante sus restos (anclas, bombardas y versos) fue identificado como un naufragio del siglo $\mathrm{XVI}^{27}$.

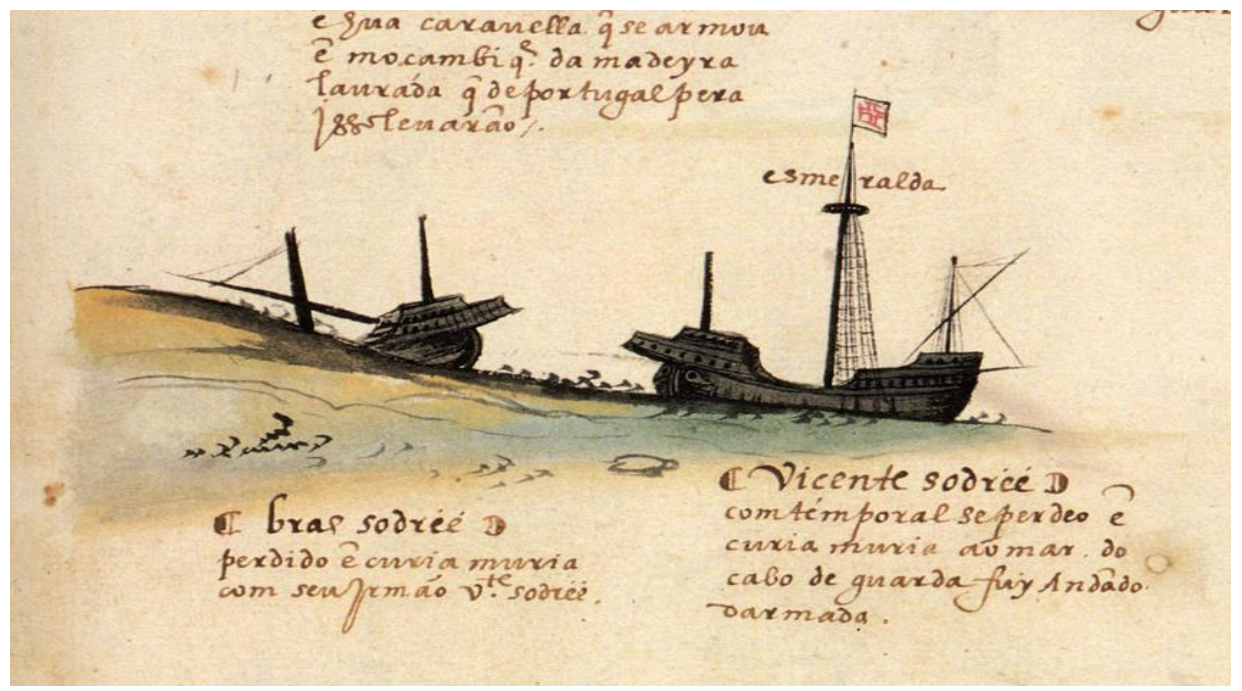

Imagen: Pérdida de los barcos de Brás y Vicente Sodré. 1568 (Wikimedia Commons)

En el caso del sector caribeño de Yucatán también se registraron varios vestigios que evidencian la navegación europea en esta región. Según los informes de la Subdirección de Arqueología Subacuática del INAH, que evalúa los trabajos realizados en el área de Banco Chinchorro, se identificaron por lo menos siete contextos arqueológicos ${ }^{28}$, que mediante los análisis comparativos de artefactos (anclas, artillería y cerámica) fueron relacionados con el siglo $\mathrm{XVI}^{29}$. De las relaciones de crónicas y relatos de la época se deduce que los primeros que navegaron por esa parte de la península yucateca fueron Diaz de Solís y Yáñez Pinzón, quienes a su regreso a España, después de concluir el reconocimiento náutico de los golfos de Honduras y Dulce, y probablemente

27 MOYA SORDO, Vera: "Riddles in the Dark: Human Behaviors in the Interpretation of a $16^{\text {th }}$ Century Wreck", en LESHIKAR-DENTON, Margaret, y Pilar LUNA ERREGUERENA (coords.): Underwater and Maritime Archaeology in Latin America and the Caribbean, Walnut Creek, Left Coast Press, 2008, pp. 109-110; "Un accidente maritimo: Procesos sociales y fenómenos naturales en un naufragio de la época de exploración y reconocimiento transatlántico en el Golfo de México", tesis de licenciatura en Arqueologia. México, ENAH-INAH. 2003, p. 129.

28 Se trata de cuatro pecios (Anclas y artilleria s. XVI, Emily II, Aracely y Falconete Escorpionidae) y tres objetos aislados (Ancla José, Anclas Aleta Perdida y Ancla Sospechosa).

29 BOJÓRQUEZ CEBALLOS, Fabián, y Laura CARRILLO MÁRQUEZ: "Informe de actividades del Programa de atención a denuncias: Inventario y Diagnóstico de Recursos Culturales Sumergidos en la Reserva de la Biosfera de Banco Chinchorro, Quintana Roo, diciembre 2006diciembre 2007", México, Archivo Técnico de la Subdirección de Arqueología Subacuática, INAH, mecanoescrito, 2008; CARRILLO MÁRQUEZ, Laura: "Inventario y Diagnóstico de Recursos Culturales Sumergidos en la Reserva de la Biosfera de Banco Chinchorro, Quintana Roo, Atención a denuncias. Informe técnico parcial 2008", México, Archivo Técnico de la Subdirección de Arqueología Subacuática, INAH, mecanoescrito, 2008. 
aprovechando la corriente, costearon la parte suroriental de Yucatán y después se dirigieron a Cuba. Así describió sus experiencias Bartolomé de Las Casas en su Historia de las Indias:

Estos dos descubridores navegaron, [...] hacia el Poniente, desde los Guanajes, y debieron llegar en paraje del golfo Dulce, aunque no lo vieron porque está escondido, sino que vieron la entrada que hace la mar entre la tierra que contiene el golfo Dulce y la de Yucatán, que es como una grande ensenada o bahía grande ${ }^{30}$. [...] Por eso Vicente Yáñez dijo que navegando desde la isla de los Guanajes, yendo la costa de luengo, descubrieron una gran bahia, [...] y que de alli descubrieron las sierras de Caria y otras tierras más adelante [...]. Y por todo esto parece que sin duda descubrieron entonces mucha parte del reino de Yucatán, sino que como después no hubo alguno que prosiguiese aquel descubrimiento, no se supo más de los edificios de aquel reino, de donde fácilmente fuera descubierta la tierra y grandezas de los reinos de la Nueva España, hasta que, acaso, se descubrió desde la isla de Cuba ${ }^{31}$.

Efectivamente, y como lo subraya en el texto citado el gran cronista indiano, hasta 1523 no tenemos ninguna noticia sobre los viajes desarrollados en la banda suroriental de la península yucateca. Sin embargo, a partir de ese año, comenzó una carrera entre diferentes facciones españolas por la influencia sobre los territorios de la actual Guatemala, Honduras y Nicaragua. El acontecimiento que lo provocó fue la expedición de Gil Gonzales Dávila, quien un año antes había explorado por el lado del Pacífico la Gran Nicoya, llegando hasta las orillas del lago de Cocibolca (actual Nicaragua), donde recogió obsequios de oro valorados en unos 90.000 pesos de oro. Este botín o rescate como acostumbraban denominarlo los españoles de la época- despertó el deseo de extraer las riquezas centroamericanas entre los cuatro centros de poder en las Indias (Nueva España, Cuba, Panamá y Santo Domingo), cuyos principales protagonistas resultaron ser Hernán Cortés, Diego Velázquez Cuéllar, Pedrarias Dávila y Diego Colón ${ }^{32}$.

Cada uno de ellos intentó enviar su expedición a dicha región para tomar el control sobre sus riquezas. Así tenemos tres personajes que concibieron los viajes de exploración y de fundación de poblados españoles en la región del golfo de Honduras. Cristóbal de Olid, uno de los capitanes que acompañó a Cortés en su desafío de la conquista de México, fue enviado por el propio conquistador en enero de 1524 con la misión de fijar una colonia y encontrar oro y plata en la región de Las Higueras. Asimismo, conforme a las indicaciones del gobernador y capitán general de la Nueva España, primero pasó a Cuba para reclutar más gente y avituallar sus navíos. En la isla se encontró con Diego Velázquez de Cuéllar, quien lo convenció para que abandonara el bando

30 Las Casas probablemente se refiere a la actual bahía de Chetumal, que Díaz de Solís y Yáñez Pinzón bautizaron como la bahía de La Navidad (LAS CASAS, Bartolomé de: Historia de las Indias, tomo II, México, FCE, 1951, p. 334).

${ }^{31}$ LAS CASAS, Bartolomé de: Historia de las Indias..., op. cit., pp. 333-334.

32 MACÍAS RICHARD, Carlos: El Caribe mexicano. Origen y conformación..., op. cit., pp. 156161. 
del primer marqués del Valle de Oaxaca, y con el respaldo del gobernador cubano comenzará la conquista de Centroamérica por su cuenta. Con ello, Cristóbal de Olid zarpó de La Habana a finales de abril de 1524 y el día 3 de mayo se encontró con la costa cercana al golfo Dulce, donde fundó el puerto, Triunfo de la Cruz, y entabló buenas relaciones con los indios de $\mathrm{Naco}^{33}$.

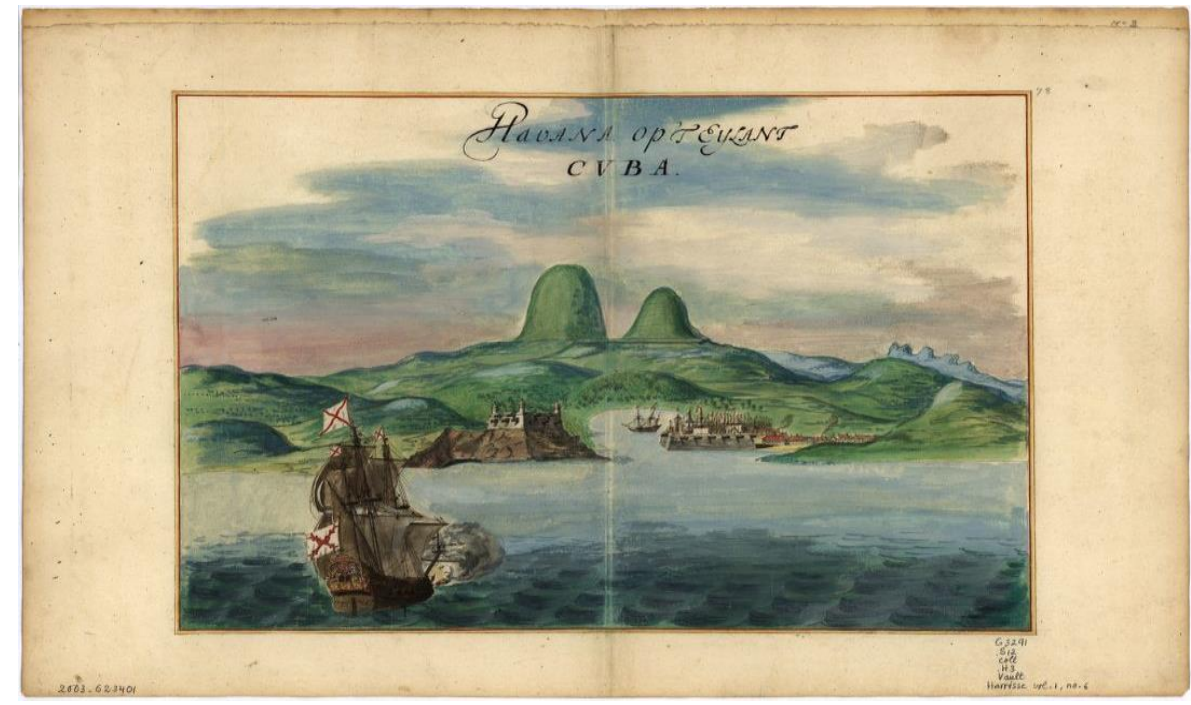

Imagen: Bahía de La Habana, ca. 1639 (Imagen de dominio público, Library of Congress)

Al mismo tiempo que la expedición de Olid, de Santo Domingo salió con autorización real otra empresa bajo el mando de Gil González Dávila, quien según las palabras de Macías Richard tuvo el honor de encabezar la primera armada española en tierra hondureña con objetivo de permanencia, poblamiento y pacificación ${ }^{34}$. La flota también se aproximó al golfo Dulce, y en un lugar apropiado González Dávila instauró la villa española Puerto Caballos ${ }^{35}$. Sin embargo, por cuestiones de salubridad el conquistador decidió mudarse a la desembocadura del golfo Dulce, donde fundó otra villa llamada San Gil de Buena Vista.

Todavía en la misma época aparecieron dos protagonistas que vale la pena mencionar en estas páginas. El primero fue Gabriel de Rojas, el capitán de la fuerza de Francisco Hernández de Córdoba ${ }^{36}$, quien primero acompañó en la exploración de la costa caribeña de Nicaragua, río San Juan y lago de Cocibolca, donde se crearon dos villas: Granada y León. Después fue a hostigar a Gil González Dávila, un enemigo mortal de Pedrarias Dávila, quien despachó la expedición de Hernández de Córdoba. Sin embargo, la persecución emprendida por Rojas no dio resultado, ya que se topó con las fuerzas de Olid y de González Dávila, que superaban a la suya, y tuvo que regresar para reencontrarse con su jefe, que residía en la ciudad de León. El otro personaje relevante en la exploración del golfo de Honduras fue el fiel capitán de Cortés, Francisco

33 HELIODORO VAlLE, Rafael: Semblanza de Cristóbal de Olid, México, FCE, 1998, pp. 4953

${ }^{34}$ MACÍAS RICHARD, Carlos: El Caribe mexicano. Origen y conformación..., op. cit., p. 166.

35 El nombre fue cambiado por Hernán Cortés a La Natividad (1525), y actualmente el topónimo es Puerto Cortés.

${ }^{36}$ Homónimo del descubridor de Yucatán, de 1517. 
de Las Casas, quien salió con cinco naos y más de 100 soldados de Veracruz a finales de 152437 .

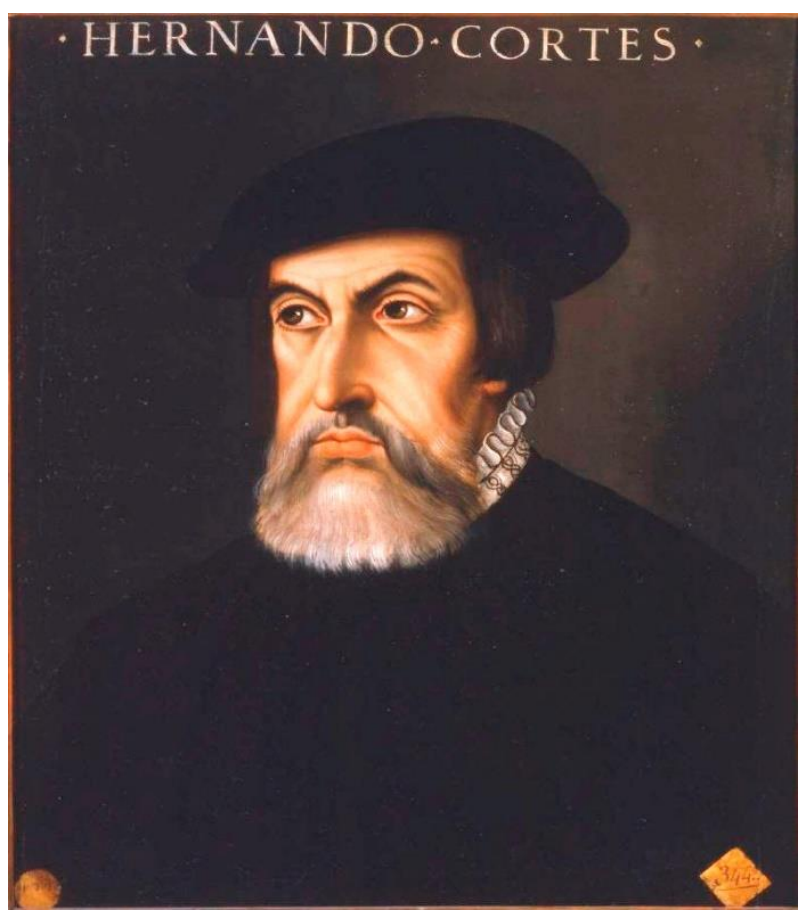

Imagen: Hernán (o Hernando) Cortés (Wikimedia Commons)

La expedición cortesiana, que como propósito albergaba el castigo contra el capitán desleal, navegó con tranquilidad alrededor de la península yucateca para llegar a Triunfo de la Cruz. Aquí se libró un enfrentamiento naval entre ambas flotillas: Francisco de Las Casas hundió algunas embarcaciones de Olid y comenzó el bloqueo del puerto. Sin embargo, en la noche cayó una furiosa tormenta que maltrató y encalló buques de la expedición cortesiana, obligando a los soldados a desembarcar en la costa, donde fueron apresados por la gente de Olid. Al mismo tiempo el capitán rebelde envió una expedición bélica, que capturó a González Dávila. La fortuna que favoreció a Cristóbal de Olid pronto terminará cuando sus propios soldados y la gente de Las Casas y González Dávila opten por aprehenderlo y llevarlo a la Nueva España. Tuvo lugar entonces un tumulto en el que Olid resultó herido y después colgado de un árbol en $\mathrm{Naco}^{38}$.

Volviendo a la temática de la navegación, digamos que Francisco de las Casas, antes de regresar a Veracruz, exploró la costa caribeña de la actual Honduras llegando hasta la punta Caxinas donde, en una caleta, el 18 de mayo de 1525 fundó el puerto de Trujillo, el cual junto con Puerto Caballos jugó un papel fundamental en los circuitos comerciales, ya que esas ciudades se convirtieron -durante el siglo XVI y primera mitad del XVII- en los únicos puntos de contacto entre la capitanía general de Guatemala y la metrópoli mediante

37 FERNÁNDEZ DE OVIEDO Y VALDÉS, Gonzalo: Historia general y natural..., op. cit, pp. 300302.

${ }^{38}$ HELIODORO VALLE, Rafael: Semblanza de Cristóbal..., op. cit., pp. 56-57. 
las "Naos o Flotilla de Honduras»39. Es importante subrayar que Trujillo y Puerto Caballos también eran puertos valiosos en el comercio caribeño, donde sobre todo se mantenía el vínculo con los mercaderes de Santiago de Cuba y Puerto de la Trinidad en la banda sur de Cuba.

En la época de la exploración española de las costas del golfo de Honduras y Yucatán, hasta 1527 los marineros y aventureros utilizaban dos puntos de referencia náutica: se trata de la bahía de Ascensión y el golfo Dulce, dejando un gran espacio marítimo que actualmente ocupa gran parte del estado de Quintana Roo (México) y Belice. Esta situación cambia con las expediciones de conquista de Yucatán llevadas a cabo por Francisco de Montejo y Alonso de Ávila, quienes en septiembre de dicho año llegaron a Cozumel, después anclaron en la pequeña bahía de Xelha, cerca de un pueblo amurallado llamado Zama (actual Tulum). En este lugar decidieron erigir el primer poblado en esta parte de la peninsula, al que llamaron Salamanca de Xelha. No obstante, ese enclave fue abandonado debido a la miseria que sufrieron los colonos y a la fatiga que encontró Montejo en la exploración de esa porción de Yucatán ${ }^{40}$.

El adelantado decidió dividir a su gente en dos grupos: uno se embarcó en las dos naos que tenía, y el otro tuvo que seguir el rumbo suroccidental por tierra. En la vanguardia de su expedición salieron 10 hombres de su confianza a bordo de la carabela y recibieron órdenes de penetrar desembocaduras, bahías, caletas e islas de Yucatán meridional. La agilidad de la embarcación garantizaba una ágil movilidad y facilitaba el abasto de provisiones en esas aguas desconocidas. Los españoles avanzaron alrededor de 80 leguas, llegando a una zona, Uaymil, donde el grupo de la mar entró en una gran bahía por la que los españoles navegaron en un batel y llegaron a la costa cerca del puerto llamado Chitemal (actual Chetumal). Alli tomaron cuatro indios, quienes informaron a Montejo de que en dicho pueblo vivia uno parecido a ellos, es decir, Gonzalo Guerrero. Este segundo intento de poblar la parte sur de Yucatán por Montejo y Ávila también fracasó ${ }^{41}$.

Todavía entre los años 1531 y 1532 se procedió a un nuevo intento de tomar el control sobre ese paraje de la península. El adelantado de Yucatán encomendó a su fiel amigo, Alonso de Ávila, apoyado en una compañía de 65 soldados, traspasar desde Campeche todo el territorio maya, alcanzando otra vez la bahía de Chetumal. En mayo de 1531 los españoles llegaron a su destino, donde fundaron la Villa Real. Permanecieron en esta localidad apenas un año debido a las amenazas de los pueblos indigenas, que finalmente expulsaron a los invasores de la región maya. El liderazgo de Gonzalo Guerrero al frente de los ejércitos indianos fue muy notable durante este período. Al final, Alonso Ávila, rodeado por sus enemigos, decidió la retirada por el único camino libre, es decir, por el mar. En 32 canoas se embarcaron 40 soldados españoles, 15

\footnotetext{
39 Fue una escuadra compuesta por dos buques que, a la altura de Jamaica, se separaban de las flotas de Nueva España y llegaban a Trujillo y Puerto Caballos (REICHERT, Rafal: "Navegación, comercio y guerra. Rivalidad por el dominio colonial en la región del Golfo de Honduras, 1713-1763", en Península, vol. VII, núm. 1, Mérida, CEPHCIS-UNAM, 2012, p. 19).

${ }^{40}$ CHAMBERLAIN, Robert S.: Conquista y Colonización..., op. cit., pp. 37-38.

${ }^{41}$ MACÍAS RICHARD, Carlos: El Caribe mexicano. Origen y conformación..., op. cit., pp. 211212.
} 
cautivos indígenas y cinco caballos para emprender su épico viaje a Honduras. Al salir de la bahía de Chetumal, la expedición se dirigió hacia Trujillo, adonde llegó después de siete meses de navegación de cabotaje, durante la cual efectuaron el reconocimiento de arrecifes, islas y ríos de Sibun, Walis, Dulce y Ulúa ${ }^{42}$.

Por último, es interesante subrayar que, a diferencia de otras subregiones del Gran Caribe, el golfo de Honduras y la parte suroriental de Yucatán —durante la época de la exploración europea y después - fueron consideradas por los españoles como aguas muy dificiles para la navegación debido a la barrera de arrecifes que se extiende desde el cabo Catoche hasta las islas de Roatán y Guanaja en la actual Honduras. Hasta la fecha, en esa área reinan tempestades y huracanes, fuertes corrientes maritimos, bajos, cayos e isletas, los peligros naturales que - sobre todo en la parte suroriental de la península yucateca-impidieron construir puertos de altura, lo que influyó en el descuido de esa región por parte de las autoridades españolas a lo largo de la época colonial. Constituyó un factor que en los siglos XVII y XVIII permitió la penetración extranjera en dicha zona, facilitándole la ventaja de conocer y aprender la navegación en esta área peligrosa, llena de trampas naturales.

\section{Del Mare Clausum a la frontera imperial, los europeos no hispanos en el Gran Caribe}

Estudiando los procesos de navegación en el Caribe, no podemos olvidar las exploraciones que, además de los españoles, protagonizaron otros europeos. Así, en la primera ola de los descubrimientos participaron con autorización real los portugueses, italianos y genoveses, entre los que destacaron Cristóbal Colón y Américo Vespucio. Sin embargo, también otras naciones del viejo continente demandaban el acceso a las nuevas tierras.

Con la entronización de Carlos I, de la dinastía de los Habsburgo, como rey de España el 28 de marzo de 1528, se otorgó a la casa de los Welser (banqueros alemanes), como parte del pago de una deuda, la exclusividad para la conquista y colonización del territorio comprendido entre el cabo de la Vela (actual Colombia) y Maracapana (actual Venezuela). De ese modo los alemanes fueron los primeros europeos no latinos que iniciaron el proceso colonizador en América. El primer gobernador de estos territorios inhóspitos fue Ambrosio Ehinger o Alfinger, quien utilizó como base la isla de La Española, donde los Welser tenían sus negocios. Desde allí salió su expedición en 1529, la cual llegó a Santa Ana de Coro (el primer asentamiento en la futura provincia de Venezuela). Después, el alemán exploró el lago de Maracaibo, donde fundó la ciudad de Nueva Núremberg (actualmente Maracaibo). Alfinger murió en 1533, asesinado por los indios Chitareros en una emboscada. Al primer gobernador de ese territorio le sucedieron otros alemanes, como Nicolás Federmann, Georg Hohermut von Speyer y Philipp von Hutten, quienes exploraron el río Orinoco, Los Llanos y la cordillera de los Andes ${ }^{43}$.

${ }^{42}$ MACÍAS RICHARD, Carlos: El Caribe mexicano. Origen y conformación..., op. cit., pp. 249250.

43 OVIEDO Y BAÑOS, José de: Historia de la conquista y población de Venezuela, Caracas, Biblioteca Ayacucho, 2004, pp. 29-74. 


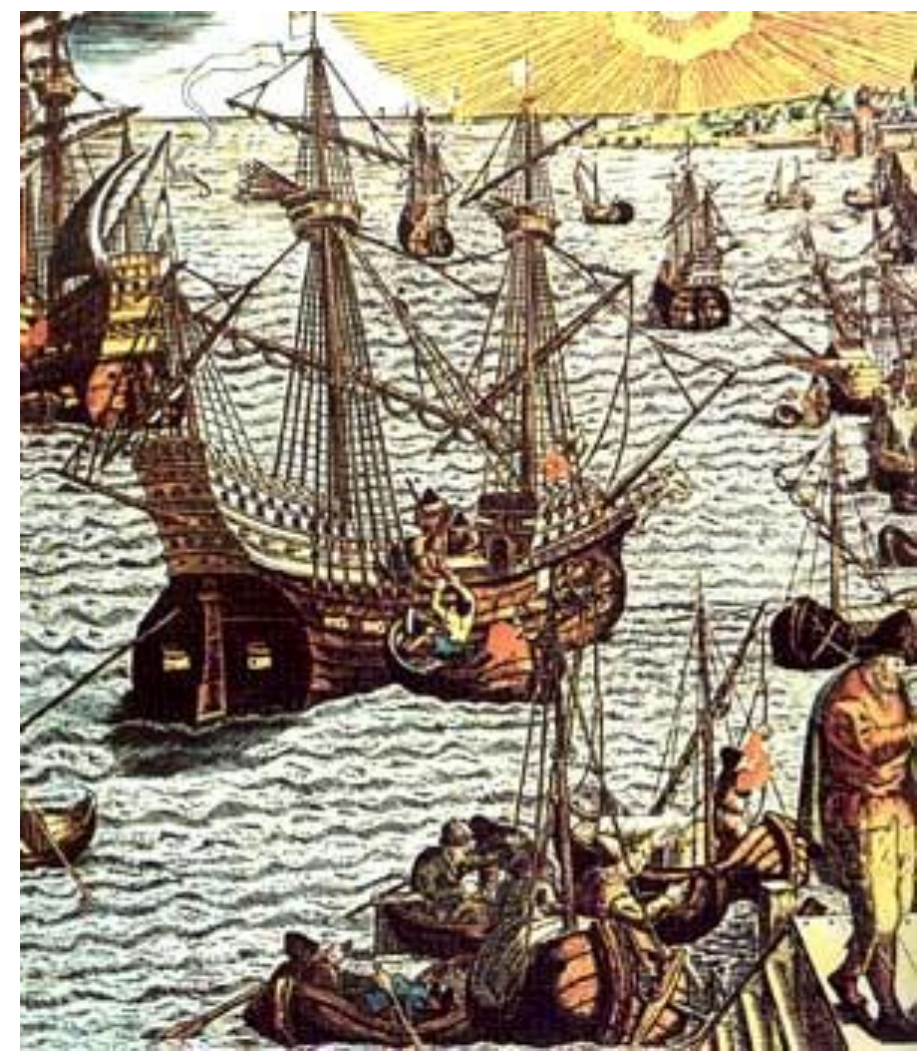

Imagen: Barcos portugueses saliendo del puerto de Lisboa (Theodore de Bry, 1593, Wikimedia Commons)

Para la Corona española, la experiencia de cesiones territoriales a los extranjeros no resultó positiva, ya que la provincia de Venezuela causó múltiples desacuerdos a nivel administrativo y jurídico, lo que la sumió en la decadencia. Cuando Felipe II accedió a regir el Imperio hispano en 1556, se prohibieron las concesiones territoriales a los foráneos. Sin embargo, eso no significó el mayor peligro para la navegación grancaribeña y transatlántica; lo peor ya había surgido con la captura de los barcos enviados por Hernán Cortés a España en 1522, cuando el corsario francés Juan Florín - mejor conocido como Florentino- capturó uno cerca de Azores, y así el mundo no hispano se enteró de las riquezas indianas ${ }^{44}$.

A partir de este acontecimiento el mundo europeo comprobó las leyendas que corrian sobre las grandes riquezas del Nuevo Mundo, suscitando el interés de Francia, Inglaterra y Holanda por participar en el reparto de esos recursos. Además de buscar el acceso legal a tales tesoros por medio del comercio sevillano y gaditano, los países europeos encontraron otras formas de intervenir en el exclusivo enriquecimiento de los españoles y lusitanos, con lo que tuvieron comienzo la piratería, el corso y el contrabando en el Atlántico, y particularmente en el Circuncaribe. En este lugar nos parece justo aludir a la respuesta del rey francés, Francisco I, a la carta de protesta de Carlos I de España sobre el asalto perpetrado por Florentino. El monarca francés respondió: ¿Cómo habian partido entre él y el rey de Portugal el mundo sin darle parte a

${ }^{44}$ REICHERT, Rafal: Sobre las olas de un mar plateado. La politica defensiva española y el financiamiento militar novohispano en la región del Gran Caribe, 1598-1700, Mérida, CEPHCISUNAM, 2013, p. 8. 
él? Y añadió que mostrasen el testamento de nuestro padre Adán, si les dejó a ellos solamente por herederos y señores de aquellas tierras que habian tomado entre ellos dos, sin dar a él ninguna de ellas; por esta causa era lícito robar y tomar todo lo que pudiese en la mar ${ }^{45}$.

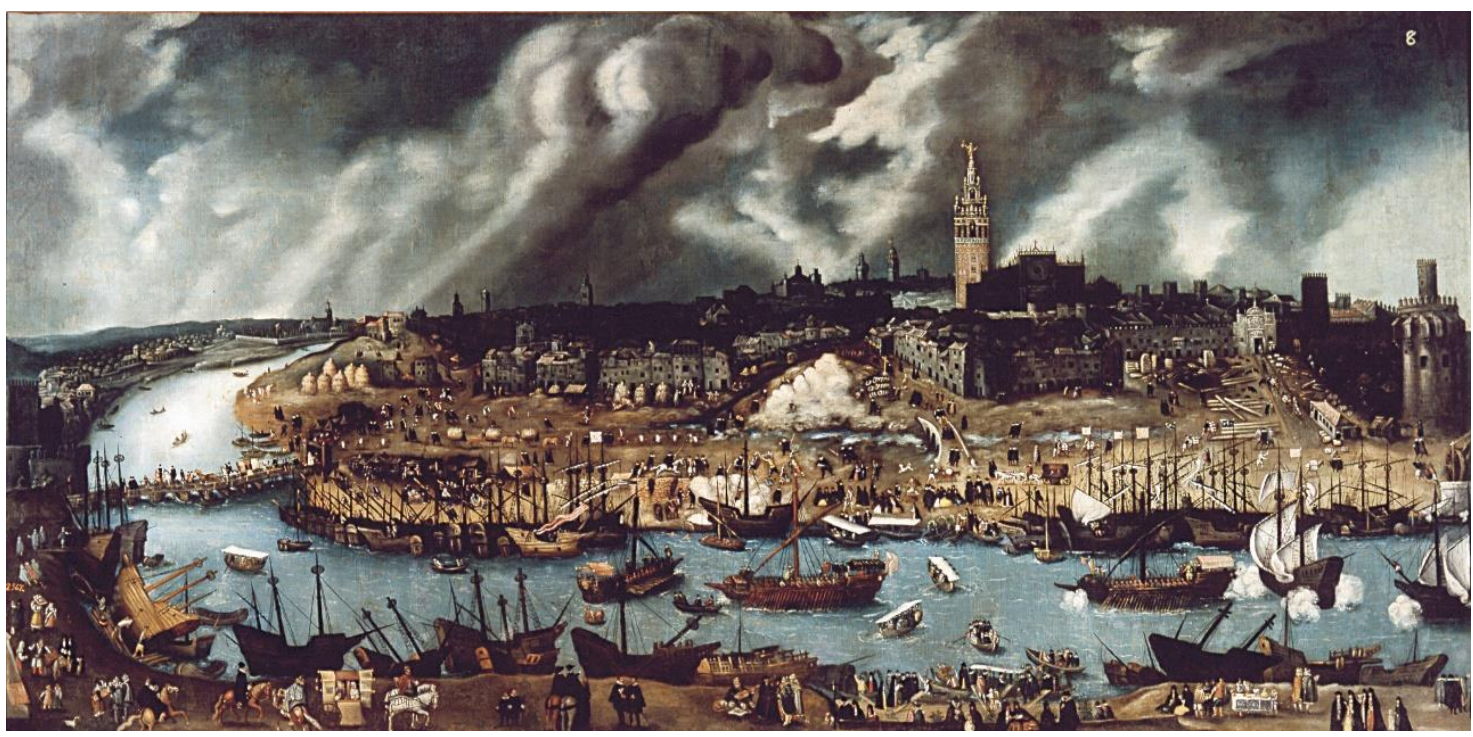

Imagen: Sevilla entre 1576-1600 (Wikimedia Commons)

Del gran número de comerciantes, militares y marineros que se dedicaron a estas empresas durante el régimen de los Habsburgo, los más conocidos fueron François Le Clerc, Jacques Soria, John Hawkins, Francis Drake, Boudewijn Hendricksz, Piet Heyn, François 1' Olonnais, Edward Mansvelt, Henry Morgan, Laurens de Graaf (Lorencillo) y Bernard Desjean (Barón de Pointis), quienes mediante sus acciones llevaron a la Corona española a plantearse un sistema defensivo eficaz para proteger tanto a los habitantes como a las rutas maritimas por las cuales navegaban los buques cargados con los tesoros americanos. Con este fin, en la década de 1540 Carlos I de España ordenó la organización de las primeras unidades de autodefensa, las milicias, compuestas por vecinos de los puertos americanos, y al mismo tiempo obligó a los comerciantes de Sevilla a realizar sus viajes a las colonias americanas en convoyes ${ }^{46}$. Finalmente, en las ordenanzas de 1564 quedó instituido el sistema de navegación segura en convoy con la división de los recorridos en dos flotas: la de Tierra Firme y la de Nueva España ${ }^{47}$.

No obstante, desde la década de 1540 las autoridades de la Corona tuvieron que enfrentarse con otro problema: la falta de defensa contra saqueos y asaltos a los principales puertos americanos, como lo demostró Francis Drake en su viaje depredador por el Gran Caribe, cuando atacó sin grandes dificultades Santo Domingo, Cartagena de Indias y San Agustín de Florida. Después de un golpe tan doloroso, Felipe II dio comienzo al gran proyecto de fortificar los puertos en la región, dando prioridad a San Juan de Puerto Rico, Cartagena,

\footnotetext{
45 APESTEGUI, Cruz: Los ladrones del mar; piratas en el Caribe: corsarios, filibusteros y bucaneros, 1493-1700, Barcelona, Lunwerg Editores, 2000, p. 21.

${ }^{46}$ HOFFMAN, Paul: The Spanish Crown and the Defense of Spanish Caribbean, 1535-1585, Louisiana, Louisiana State University Press, 1980, p. 19.

47 HARING, Clarence H.: Comercio y navegación..., op. cit., p. 261.
} 
Portobelo, La Habana y San Juan de Ulúa. A cargo de la inmensa obra fue situado un arquitecto militar italiano, Bautista Antonelli, acompañado por Juan de Tejeda (gobernador de Cuba). Antonelli y Tejeda comenzaron su labor en 1586, inspeccionando y diseñando nuevas fortificaciones al estilo italiano en los puntos claves del Golfo de México y del Caribe ${ }^{48}$.

Esos puertos militarizados se denominaron "llaves del Nuevo Mundo", debido a su importancia estratégica en la protección de las posesiones españolas y las rutas marítimas entre América y la metrópoli. Es importante subrayar que desde el inicio de las conquistas de Nueva España y de Perú, el mar Caribe se convirtió en un núcleo del poder español que era preciso reforzar, apuntalando los recursos e invirtiendo cada vez más para detener la creciente penetración extranjera. En los tres siglos del período colonial ninguna otra región superó la posición privilegiada que ocupaba en la estrategia defensiva española el Gran Caribe, el principal baluarte de las Indias con que tuvieron que enfrentarse las potencias europeas en sus intentos de apropiarse de tierras y riquezas americanas ${ }^{49}$.

En el siglo XVII este antemural contuvo invasiones a los dos virreinatos y, en última instancia, configuró una barrera para reemplazar los planes expansionistas de Francia, Inglaterra y Holanda a través de las "conquistas comerciales" llevadas a cabo por mercaderes de esos paises. Sin embargo, durante los reinados de Felipe IV (1621-1665) y Carlos II (1665-1700) no se consiguió evitar las ocupaciones de islas de las Antillas Menores, como San Cristóbal, Martinica, Guadalupe y San Martín, entre otras, abandonadas y consideradas por los españoles tierras inútiles para la política colonial. Tampoco pudo la Corona impedir la pérdida del control sobre la isla de Jamaica (1655) y la banda noroccidental de La Española (1697), que quedaron en manos de ingleses y franceses. En la segunda mitad del siglo XVII, esos espacios se convirtieron en trampolines para acciones bélicas de piratas, corsarios, bucaneros y filibusteros, y en el s. XVIII fueron importantes núcleos mercantes, azucareros $\mathrm{y}$ bases navales estratégicas ${ }^{50}$.

Si nos referimos nuevamente al golfo de Honduras y la parte suroriental de la península de Yucatán, los primeros extranjeros se presentaron en la zona en julio de 1558, cuando doscientos piratas franceses desembarcaron de dos naves y atacaron la villa de Trujillo, robaron y quemaron el poblado, llevándose alrededor de 100.000 pesos. Este primer ataque fue informado a la Real Audiencia de Guatemala, la cual ordenó dotar de más seguridad a Puerto Caballos y Trujillo, que como se ha mencionado eran los dos puertos de mayor importancia de la capitanía general. Sin embargo, las incursiones piráticas continuaron, lo que obligó al rey hispano a dictar el 25 de marzo de 1561 una orden al gobernador de la provincia de Honduras para que se previniese contra

48 CALDERÓN QUIJANO, José Antonio: Las fortificaciones españolas en América y Filipinas, Madrid, Mapfre, 1996, p. 169.

49 REICHERT, Rafal: Sobre las olas de un mar plateado..., op. cit., p. 9.

50 Ibid., p. 10. 
el peligro de la piratería ${ }^{51}$. Los ataques a los puertos y embarcaciones españoles en la región del Golfo de Honduras aumentaron con la guerra de los Treinta Años (1618-1648), en la que España participó a partir de 1621, y tuvo que enfrentarse con los feroces corsarios holandeses, que se ubicaron en Las Higueras como su área de operaciones e interceptaciones, capturando en tres ocasiones la flotilla de Honduras, de la cual obtuvieron buenos botines en metales preciosos y otras materias primas. Los ataques más famosos corrieron a cargo de Schouten en 1624, Lucifer en 1627 y Booneter en $1630^{52}$.

No podemos olvidar, en fin, a los cortadores de madera provenientes sobre todo de Inglaterra, quienes extraian palo de Campeche y otras maderas preciosas de los ríos Walis, Nuevo y Hondo, los cuales desembocan en la Bahía de Chetumal. Según Steven Forbes, los primeros no hispanos llegaron a la actual Belice en 1637, y fueron los náufragos de un navío que encalló en el arrecife que guarda la entrada a la bahía. Esa actividad fue más intensa a partir de 1655 (toma de Jamaica por los ingleses), y en especial desde 1677, cuando el comercio de palo de tinte se volvió para los ingleses un comercio muy rentable 53 .

Esta creciente presencia extranjera, tanto en la bahía de Chetumal como en la laguna de Términos, donde se asentaron ranchos de cortadores de madera, provocó una fuerte reacción entre las autoridades españoles, que en el período 1702-1717 primero emprendieron una victoriosa lucha en la laguna, para después comenzar a "limpiar" los territorios de la capitanía yucateca, proceso que se intensificó en 1722 y perduró con mayor o menor frecuencia hasta 1763, cuando se firmó el Tratado de París, por el que la Corona española otorgó a los británicos el derecho de extraer las maderas preciosas ${ }^{54}$.

Al término de este apartado sobre la navegación no hispana en el Gran Caribe, y especialmente en la zona del suroriente de Yucatán, parece conveniente presentar la opinión del almirante de la Armada de Barlovento, Rodrigo de Torres y Morales, quien en 1726 realizó un recorrido con el situado por islas caribeñas y quiso fondear en las cercanias de la isla Cozumel. Pero como subraya, tuvo mucha dificultad por poca experiencia de marineros que se mostraron despistados ante los arrecifes y corrientes que bordeaban la isla. Un episodio parecido le sucedió dos meses más tarde cuando el gobernador de Yucatán, don Antonio de Figueroa y Silva, solicitó el apoyo de la Armada para perseguir a los cortadores de palo de tinte en Walis. Entonces Rodrigo de Torres le respondió que a causa de no conocer la peligrosa navegación de aquellos mares, donde son muchos los arrecifes y ninguna la experiencia de los pilotos, se niega

51 RUBIO SÁNCHEZ, Manuel: Comercio terrestre de y entre las provincias de Centroamérica, Guatemala, Editorial del Ejército, 1973, p. 97.

52 REICHERT Rafal: "Entre la paz y la guerra, el gasto militar novohispano en la región del Gran Caribe (1609-1648)", en ALVES CARRERA, Ángelo, y Ernest SÁNCHEZ SANTIRÓ (coords.): Guerra y Fiscalidad en la Iberoamérica Colonial (siglos XVII-XIX/Guerra e Fiscalidade na Ibero-América Colonial (Séculos XVII-XIX), Brasil-México, Universidade Federal de Juiz de Fora e Instituto Mora, 2012, p. 51.

53 FORBES, Steven: The Baymen of Belize and how they wrested British Honduras from the Spaniards, Sheldon Press, London, 1920, p. 9.

54 REICHERT Rafal: "Entre la paz y la guerra, el gasto militar...», art. cit., pp. 27-33. 
a cumplir con la demanda y añade que los británicos estaban bien preparados en la travesia por esas aguas llenas de cayos, bancos, islas y arrecifes ${ }^{55}$.

\section{Bibliografía}

APESTEGUI, Cruz: Los ladrones del mar; piratas en el Caribe: corsarios, filibusteros y bucaneros, 1493-1700, Barcelona, Lunwerg Editores, 2000.

BOJÓRQUEZ CEBALLOS, Fabián, y Laura CARRILLO MÁRQUEZ: "Informe de actividades del Programa de atención a denuncias: Inventario y Diagnóstico de Recursos Culturales Sumergidos en la Reserva de la Biosfera de Banco Chinchorro, Quintana Roo, diciembre 2006-diciembre 2007", México, Archivo Técnico de la Subdirección de Arqueología Subacuática, INAH, mecanoescrito, 2008.

BOORSTIN, Daniel: Los descubridores, Barcelona, Editorial Crítica, 1983, p. 178.

CALDERÓN QUIJANO, José Antonio: Las fortificaciones españolas en América y Filipinas, Madrid, Mapfre, 1996.

CARRILLO MÁRQUEZ, Laura: "Inventario y Diagnóstico de Recursos Culturales Sumergidos en la Reserva de la Biosfera de Banco Chinchorro, Quintana Roo, Atención a denuncias. Informe técnico parcial 2008", México, Archivo Técnico de la Subdirección de Arqueologia Subacuática, INAH, mecanoescrito, 2008.

CHAMBERLAIN, Robert S.: Conquista y Colonización de Yucatán (1517-1550), México, Porrúa, 1982.

COLÓN, Cristóbal: Diario de a bordo, Madrid, Grupo EDAF, 2006, pp. 194195.

LAS CASAS, Bartolomé de: Historia de las Indias, tomo II, México, FCE, 1951.

OVIEDO Y BAÑOS, José de: Historia de la conquista y población de Venezuela, Caracas, Biblioteca Ayacucho, 2004.

DÍAZ DEL CASTILLO, Bernal: Historia verdadera de la conquista de la Nueva España, Madrid, Espasa-Calpe, 1975.

ELIOT MORISON, Samuel: El Almirante de la Mar Océano. Vida de Cristóbal Colón, México, FCE, 1991.

FAVIER, Jean: Los grandes descubrimientos. De Alejandro a Magallanes, México, FCE, 1995.

FERNÁNDEZ DE OVIEDO Y VALDÉS, Gonzalo: Historia general y natural de las Indias, islas y tierra firme del mar océano, tercera parte, tomo IV, Madrid, Imprenta de la Real Academia de la Historia, 1855.

FERNÁNDEZ ARMESTO, Felipe: Amerigo. The man who gave his name to America, London, Weidenfeld \& Nicolson, 2006.

FORBES, Steven: The Baymen of Belize and how they wrested British Honduras from the Spaniards, Sheldon Press, London, 1920.

55 RUBIO MAÑÉ, José Ignacio: El Virreinato, III: expansión y defensa, segunda parte, México, FCE-UNAM, 1983, p. 336. 
GARCÍA GARRALÓN, Marta: "La formación de los pilotos de la Carrera de Indias en el siglo XVIII", en Anuario de Estudios Atlánticos, núm. 55, Las Palmas de Gran Canaria, 2009, pp. 159-228.

GRAFENSTEIN GAREIS, Johanna von: Nueva España en el Circuncaribe, 1779-1808. Revolución, competencia imperial y vínculos intercoloniales, México, UNAM, 1997.

HARING, Clarence H.: Comercio y navegación entre España y las Indias, México, FCE, 1984.

HELIODORO VALLE, Rafael: Semblanza de Cristóbal de Olid, México, FCE, 1998.

HOFFMAN, Paul: The Spanish Crown and the Defense of Spanish Caribbean, 1535-1585, Louisiana, Louisiana State University Press, 1980.

LÓPEZ PIÑERO, José María: El arte de navegar en la España del Renacimiento, Barcelona, Editorial Labor, 1979.

MACÍAS RICHARD, Carlos: El Caribe mexicano. Origen y conformación, siglos XVI y XVII, Chetumal-México, Universidad de Quintana Roo-Porrúa, 2006.

MARTÍNEZ, José Luis: Hernán Cortés, Documentos Cortesianos, México, FCEUNAM, 1990.

MOYA SORDO, Vera: "Riddles in the Dark: Human Behaviors in the Interpretation of a $16^{\text {th }}$ Century Wreck", en LESHIKAR-DENTON, Margaret, y Pilar LUNA ERREGUERENA (coords.): Underwater and Maritime Archaeology in Latin America and the Caribbean, Walnut Creek, Left Coast Press, 2008, pp. 103-112.

MOYA SORDO, Vera: "Un accidente maritimo: Procesos sociales y fenómenos naturales en un naufragio de la época de exploración y reconocimiento transatlántico en el Golfo de México", tesis de licenciatura en Arqueología, México, ENAH-INAH. 2003.

ODRIOZOLA OYARBIDE, Lourdes: Construcción Naval en el País Vasco XVI-XIX. Evolución y Análisis, San Sebastián, Beca Angel Apraiz Eusko Ikaskuntza, 1996.

ORTWIN SAUER, Carl: Descubrimiento y dominación española del Caribe, México, FCE, 1984.

PARRY, John H., y Philip M. SHARLOCK: Short History of the West Indies, New York, Macmillan, 1971.

REICHERT Rafal: "Entre la paz y la guerra, el gasto militar novohispano en la región del Gran Caribe (1609-1648)", en ALVES CARRERA, Ángelo y Ernest SÁNCHEZ SANTIRÓ (coords.: Guerra y Fiscalidad en la Iberoamérica Colonial (siglos XVII-XIX/Guerra e Fiscalidade na Ibero-América Colonial (Séculos XVII-XIX), Brasil-México, Universidade Federal de Juiz de Fora e Instituto Mora, 2012, pp. 39-64.

- "Navegación, comercio y guerra. Rivalidad por el dominio colonial en la región del Golfo de Honduras, 1713-1763", en Península, vol. VII, núm. 1, Mérida, CEPHCIS-UNAM, 2012, pp. 13-37. 
- Sobre las olas de un mar plateado. La política defensiva española y el financiamiento militar novohispano en la región del Gran Caribe, 15981700, Mérida, CEPHCIS-UNAM, 2013.

RUBIO MAÑÉ, José Ignacio: El Virreinato, III: expansión y defensa, segunda parte, México, FCE-UNAM, 1983.

RUBIO SÁNCHEZ, Manuel: Comercio terrestre de y entre las Provincias de Centroamérica, Guatemala, Editorial del Ejército, 1973.

WILLIAMS, Eric: De Colón a Castro: la historia del Caribe 1492-1969, México, Instituto Mora, 2009. 